Lavin, T., Song, Y., Bakker, A.J., McLean, C.J., Macdonald, W.A., Noble, P.B., Berry, C.A., Pillow, J.J . \& Pinniger, G.J. (2013). Developmental Changes in Diaphragm Muscle Function in the Preterm and Postnatal Lamb. PEDIATRIC PULMONOLOGY, 48(7), 640648.

(c) 2013 Wiley Periodicals, Inc.

This is pre-copy-editing, author-produced version of an article accepted for publication in Pediatric Pulmonology following peer review. The definitive published version (see citation above) is located on the article abstract page of the publisher, Wiley Online Library.

This version was made available in the UWA Research Repository on 26 June 2014 in compliance with the publisher's policies on archiving in institutional repositories.

Use of the article is subject to copyright law. 


\title{
Developmental changes in diaphragm muscle function in the preterm and postnatal lamb
}

T. Lavin $\mathrm{BSc}^{1,2, \dagger}$, Y. Song $\mathrm{PhD}^{1,2, \dagger}$, A.J. Bakker $\mathrm{PhD}^{1}$, C.J. McLean $\mathrm{BSc}^{2}$, W.A. Macdonald $\mathrm{PhD}^{2}$, P.B. Noble $\mathrm{PhD}^{1,2}$, C.A. Berry $\mathrm{PhD}^{2}$, J.J. Pillow $\mathrm{PhD}^{2,3}$ \& G.J. Pinniger $\mathrm{PhD}^{1 *}$

1. School of Anatomy, Physiology and Human Biology, The University of Western Australia, Crawley, Western Australia, Australia, 6009.

2. Centre for Neonatal Research and Education, School of Women's and Infants' Health, The University of Western Australia, Crawley, Western Australia, Australia, 6009.

3. King Edward Memorial Hospital, Women and Newborn Health Service, Western Australia, Australia, 6008

$\dagger$ Both authors contributed equally.

\author{
* Corresponding Author \\ Gavin J Pinniger \\ M309, School of Anatomy, Physiology and Human Biology \\ University of Western Australia \\ 35 Stirling Highway \\ Crawley, Western Australia \\ Australia, 6009 \\ Ph: +61 864883380 \\ Fax: +61 864881025 \\ Email: gavin.pinniger@uwa.edu.au
}

\section{Statement of Financial Support}

Part of this work was funded by a National Health and Medical Research Council Project Grant (APP 1010665), a Sylvia and Charles Viertel Senior Medical Research Fellowship (JJP) and a Starter Grant from the Women and Infants Research Foundation, WA.

\section{Abbreviated Title: Functional development of the preterm diaphragm}




\section{SUMMARY}

Rationale: The preterm diaphragm is structurally and functionally immature, potentially contributing to an increased risk of respiratory distress and failure. We investigated developmental changes in contractile function and susceptibility to fatigue of the costal diaphragm in the fetal lamb to understand factors contributing to the risk of developing diaphragm dysfunction and respiratory disorders. We hypothesized that the functional capacity of the diaphragm will vary with maturational stage as will its susceptibility to fatigue.

Methods: Lambs were studied at 75, 100, 125, 145, 154, 168 and $200 \mathrm{~d}$ postconceptional age (term=147 d). Lambs were euthanized (sodium pentobarbitone, $100 \mathrm{mg} / \mathrm{kg}$ ) either at delivery or immediately prior to post-mortem for postnatal lambs. Contractile function was assessed on longitudinal strips of intact muscle fibres and the remaining tissue frozen in liquid nitrogen for analysis of myosin heavy chain (MHC) mRNA expression and protein content.

Results: Fetal development of diaphragm function was characterized by a significant increase in maximum specific force, increased susceptibility to fatigue, reduced twitch contraction times, and a progressive increase in MHCI and MHCII protein content. Postnatally, there was a progressive decrease in the susceptibility to fatigue that coincided with an increase in the MHC I:II protein ratio.

Conclusion: These data indicate that the functional capacity of the diaphragm varies with maturational age and may be an important determinant of the susceptibility to preterm respiratory failure.

\section{KEYWORDS}

Respiratory Muscle, Ventilation, Skeletal Muscle, Fatigue, Ontogeny 


\section{INTRODUCTION}

A functional respiratory system is vital for the successful establishment of unsupported spontaneous breathing. Due to developmental immaturity of the gas exchanging regions of the lung, preterm infants are prone to respiratory distress and failure during transition to postnatal life. Generation of negative inspiratory pressures and efficient independent ventilation are also critically dependent on a functioning diaphragm and intercostal muscles. However, little is known about the integrity of the respiratory muscle pump in the premature infant.

Like the lung, the diaphragm is also structurally and functionally immature at birth in the preterm infant. Preterm infants who breathe spontaneously at birth may develop insidious respiratory insufficiency over the first minutes, hours or days of life, often necessitating mechanical ventilation. These infants have lower measured twitch transdiaphragmatic pressures compared to term infants (1), indicating that functional immaturity of the diaphragm may contribute to preterm respiratory failure. Diaphragmatic integrity may be compromised further by adverse environmental exposures in utero (antenatal steroids, infection, under nutrition) or by the postnatal disuse atrophy associated with the use of controlled mechanical ventilation and the use of paralysing agents.

There are notable differences between the immature and adult diaphragm in myosin heavy chain (MHC) content, metabolism, contractile function and oxidative capacity. Diaphragm fibre type analysis in a range of species indicate a low content of slow Type I (fatigue resistant) muscle fibres in the immature diaphragm ( $<10 \%$ at birth) versus a higher content in the mature diaphragm ( 50-60\%) (2-4). In humans, adult proportions of Type I fibres are not attained until 1 year (3). Additionally, embryonic 
and neonatal MHC isoforms are evident in fetal and early life, but progressively disappear with advancing maturation.

The functional consequences of developmental fibre type changes are poorly understood. For example, Type II MHC preponderance in the fetal respiratory muscles might indicate predilections to respiratory failure and fatigue. Although increased fatigability of the diaphragm was reported after direct phrenic nerve stimulation in full-term newborn rabbit pups compared to adult rabbits (5), several others report the opposite finding of a high fatigue resistance in the diaphragm of newborn rats (6), cats (7) and baboons (8). Subsequent increased fatigability during postnatal development is also contrary to the increased proportion of fatigue resistant Type I fibres reported in the adult compared to the newborn diaphragm (3).

These data suggest that the relationship between MHC expression, contractile function and fatigability is less robust in fetal muscle compared to adult muscle, likely due to the influence of other cellular factors involved in contractile function and endurance. In addition to changes in MHC fibre content, pre-natal development is also characterized by changes in intracellular $\mathrm{Ca}^{2+}$ handling (9), oxidative capacity $(10,11)$, and myofilament structure (9) which will impact on force generation and susceptibility to fatigue and damage. These developmental changes occur at different rates and may impact on the resilience of the immature newborn infant to increased respiratory mechanical loads and the inflammatory and metabolic challenges that occur after birth. Therefore, the level of functional development of the diaphragm will vary with gestational age as will its contribution to respiratory failure due to diaphragmatic fatigue, damage and/or contractile dysfunction in preterm babies.

Developmental changes in fibre type composition and contractile properties of the diaphragm have been examined primarily in small laboratory animals. However, the 
relevance of these observations to human diaphragm development is limited as most developmental changes in rodents occur ex utero while the majority of development in human neonates occurs in utero (12). Furthermore, small laboratory animals have a higher proportion of Type II muscle fibres and a higher respiratory rate compared to humans and larger mammals which may impact on the contractile properties of the diaphragm and therefore affect the susceptibility to muscle damage and fatigue (13).

A more representative model of the in utero development of the diaphragm in human neonates may be gained from a comparable ovine animal model. The ovine model is also a convenient model to study the effect of chronic external influences such as nutritional imbalance, infection and steroid exposures on the structural and functional integrity of the immature diaphragm. Although the ontogeny of skeletal limb muscle in the lamb has been documented (2), there are no physiological data on the ovine fetal diaphragm. Therefore, we investigated developmental changes in contractile function of the lamb costal diaphragm to understand factors contributing to the risk of developing respiratory disorders and diaphragm dysfunction at different fetal and postnatal ages. We hypothesized that the functional capacity of the diaphragm will vary with maturational stage as will its susceptibility to fatigue and stretch-induced damage. In addition, these data will provide a baseline to inform subsequent studies investigating how antenatal factors may influence diaphragm function at time of preterm birth. 


\section{MATERIALS AND METHODS}

\section{Animals, surgery and preparation}

Fetuses were delivered from sedated (10 mg/kg ketamine, Parnell Labs; $0.02 \mathrm{mg} / \mathrm{kg}$ medetomidine, Pfizer Animal Health, NSW, Australia) date mated pregnant Merino ewes via caesarean section after spinal regional anaesthetic block (2\% lignocaine, 3mL, $60 \mathrm{mg})$ at $75 \mathrm{~d}(\mathrm{n}=5), 100 \mathrm{~d}(\mathrm{n}=8), 125 \mathrm{~d}(\mathrm{n}=14)$, and $145 \mathrm{~d}(\mathrm{n}=9)$ gestation (term=147 d). Ewes and their lambs were euthanized at delivery (sodium pentobarbitone, 100 mg/kg, Valabarb®, Pitman-Moore, Australia). Additional datemated ewes delivered spontaneously at term ( $147 \mathrm{~d}$ gestation) and their offspring were grown to $1 \mathrm{w}$ (154 d postconceptional age; $n=5), 3 \mathrm{w}(168 \mathrm{~d} ; \mathrm{n}=6)$ and $7 \mathrm{w}(200$ $\mathrm{d} ; \mathrm{n}=4$ ). All lambs were exsanguinated prior to post-mortem. All animal procedures were approved by the Animal Ethics Committee of the University of Western Australia.

\section{Tissue collection}

The fetal diaphragm was dissected with the ribs and central tendon attached and hemisected. Contractile function was assessed on longitudinal strips of muscle fibres isolated from the costal portion of the right hemi-diaphragm. Sections from the costal portion of the left hemi-diaphragm were frozen in liquid nitrogen for analysis of MHC mRNA expression and protein content.

\section{Muscle contractile properties}

The hemi-diaphragm was dissected into 3-5 mm wide longitudinal strips and mounted in an in vitro muscle test system (model 1205, Aurora Scientific In., Canada) containing physiological saline solution (in mM: $\mathrm{NaCl}, 109 ; \mathrm{KCl}, 5 ; \mathrm{MgCl}_{2}, 1 ; \mathrm{CaCl}_{2}$, 
4; $\mathrm{NaHCO}_{3}, 24 ; \mathrm{NaH}_{2} \mathrm{PO}_{4}, 1$; sodium pyruvate, 10), continuously bubbled with $95 \%$ $\mathrm{O}_{2} / 5 \% \mathrm{CO}_{2}$. The solution was maintained at $25^{\circ} \mathrm{C}$, which is optimal for the maintenance of in vitro skeletal muscle force (14).

The preparation was manually adjusted to the optimum muscle length $\left(\mathrm{L}_{0}\right)$ at which maximum isometric twitch force $\left(\mathrm{P}_{\mathrm{t}}\right)$ was recorded. The time course of twitch contractions were analysed for time-to-peak (TTP) and half-relaxation time (1/2RT). The force-frequency relationship was determined between 5 - $80 \mathrm{~Hz}$ from which the maximum tetanic force $\left(\mathrm{P}_{0}\right)$ was determined. Fatigue resistance was evaluated by stimulating once every second for $330 \mathrm{~ms}$ at the optimal frequency for a total of $150 \mathrm{~s}$. The fatigue index was determined from the ratio of the force produced during the $150^{\text {th }}$ contraction relative to the $1^{\text {st }}$ contraction (2), in which a higher number indicates a greater fatigue resistance. Recovery after the fatigue protocol was evaluated by recording $\mathrm{P}_{\mathrm{o}}$ at $2,5,10,20,30$, and 40 min after the fatigue protocol or until $\mathrm{P}_{\mathrm{o}}$ had recovered to pre-fatigue levels.

The susceptibility to muscle damage was determined from a series of 5 lengthening (eccentric) contractions at 2 min intervals. For each lengthening contraction, a stretch of $10 \%$ of $\mathrm{L}_{0}$ was applied during the isometric plateau phase of a maximal tetanic contraction. $\mathrm{P}_{\mathrm{o}}$ was recorded before and at 2, 5 and 10 mins after the lengthening contraction protocol. The severity of damage was determined by the mean reduction in $\mathrm{P}_{\mathrm{o}}$ after the stretch.

Finally, the rib and tendon were removed from the diaphragm strip and the wet muscle weight recorded. Cross sectional area was calculated from the muscle mass (g), $\mathrm{L}_{\mathrm{o}}(\mathrm{mm})$ and density of skeletal muscle $\left(1.056 \mathrm{~g} \cdot \mathrm{cm}^{-2}\right)$. To account for slight differences in the size of the dissected diaphragm strips, the absolute force was normalized for cross-sectional area and expressed as specific force $\left(\mathrm{N} \cdot \mathrm{cm}^{-2}\right)$. 


\section{MHC Fibre Characteristics}

\section{Gene Expression Assay}

Total RNA was isolated from 30 mg homogenized diaphragm tissue using the RNeasy Mini kit (Qiagen Pty Ltd., Doncaster, Australia) according to manufacturer's instructions. Contaminating genomic DNA was removed by an on-column DNaseI digestion (DNaseI digestion kit, Qiagen Pty Ltd., Doncaster, Australia). Isolated RNA was reverse transcribed into complementary DNA (cDNA) in a $20 \mu \mathrm{L}$ reaction (QuantiTect ${ }^{\circledR}$ Reverse Transcription Kit, Qiagen Pty Ltd., Doncaster, Australia). Primers used for MHC slow and MHC fast were designed on ovine-specific mRNA sequences. Specific products were amplified and detected on the Rotor-gene 3000 real time PCR system (Corbett Life Science) using Rotor-Gene SYBR Green PCR Kit (Qiagen Pty Ltd., Doncaster, Australia) following the manufacturer's instructions. The cycling conditions for all genes were as follows: $5 \mathrm{~m}$ at $95^{\circ} \mathrm{C}, 35-40$ cycles of $5 \mathrm{~s}$ at $95{ }^{\circ} \mathrm{C}, 20 \mathrm{~s}$ at optimised annealing temperature (Table 1 ) and $20 \mathrm{~s}$ at $72{ }^{\circ} \mathrm{C}$. The expression levels of genes of interest were normalized into 18S RNA (15) using the 2 ${ }^{\Delta \Delta \mathrm{CT}}$ method (16) and presented as a fold change relative to the full term group (145 d).

\section{Western Blot Analysis}

Muscle samples were homogenized in ice-cold lysis buffer containing 20 mM HEPES pH 7.7, 2.5 mM MgCl, 0.1 mM EDTA, 20 mM $\beta$-glycerophosphate, $100 \mathrm{mM} \mathrm{NaCl}$, 0.1\% Triton 100, $500 \mu \mathrm{M}$ DTT, $100 \mu \mathrm{M} \mathrm{Na} \mathrm{Vo}_{4}, 100 \mathrm{mM}$ PMSF, 0.01\% NP40 and protease inhibitor cocktail tablet (Roche, Castle Hill, Australia). Homogenates were subjected to 6 cycles of freeze - thaw then centrifuged (10 000 g, 25 min, $4{ }^{\circ} \mathrm{C}$ ). Total protein concentration in the supernatant was measured by Bradford protein assay (17). Equal amounts of total lysate proteins (50 $\mu \mathrm{g}$ ) were separated by $12 \%$ SDS-PAGE 
and transferred to nitrocellulose membranes. After blocking in PBS containing 5\% non-fat dry milk, the membranes were incubated with primary antibodies against MHC slow (1:500, Novocastra), MHC fast (1:500, Novocastra), and $\alpha$-Tubulin (1:1000, Cell Signalling) for $2 \mathrm{~h}$ at room temperature. Bound antibodies were detected with 1:1000 dilutions of either anti-rabbit or mouse (Cell Signalling) immunoglobulin conjugated with horseradish peroxidise (HRP). The blots were developed by adding a SuperSignal ${ }^{\circledR} \quad$ West Pico Chemiluminescent Substrate (Thermo Scientific, Massachusetts, USA) and quantified by computerized image analysis (ImageQuant TM 350, GE Healthcare). To avoid the variation across membranes arising from different exposure time and transferring/blotting efficiency, a same control sample was added in each test. The values for each protein were standardized with the control sample and then normalized into $\alpha$-Tubulin abundance.

\section{Statistical Analysis}

Parametric data were analysed using one-way or two-way ANOVA as appropriate with post hoc analysis (Holm-Sidak test) to identify differences between independent groups. For non-parametric data, a Kruskal Wallis ANOVA on ranks was employed using Dunn's post-hoc analysis. Correlations between dependent variables and postconceptional age are presented as Pearson correlation coefficients or Spearman $r$ for non-parametric data. An alpha-level of 0.05 was used to compare differences between independent groups and to determine overall significance. Values are means \pm SEM, unless specified otherwise. 


\section{RESULTS}

\section{Animals}

The mean body weight and optimal muscle length $\left(\mathrm{L}_{0}\right)$ are presented in Table 2. As expected, both body weight and $\mathrm{L}_{0}$ increased significantly with increasing postconceptional age $(\mathrm{p}<0.01)$.

\section{Diaphragm Contractile Properties}

\section{Specific force and Force Frequency}

There was a significant main effect of postconceptional age on maximum specific force ( $p<0.01$ ). Maximum force increased by $\sim 2$-fold from 128 d to $145 \mathrm{~d}$ postconceptional age (Fig 1A). However, there was no significant change in maximum specific force during postnatal development.

The relationship between diaphragm force and stimulation frequency was evaluated between $5-80 \mathrm{~Hz}$ for each postconceptional age. The force-frequency relationships showed a consistent change with increasing postconceptional age. However for clarity, data are only presented for three gestational ages spanning the pre-term (128 d), near-term (145 d) and early postnatal (154 d) time points (Figure 1B and 1C). The specific force was significantly lower at all frequencies in the pre-term animals (Fig $1 \mathrm{~B} ; \mathrm{p}<0.001)$. When normalized to the maximum specific force in each potconceptional age (Fig 1C), the normalized force-frequency relationships were shifted to the right at increasing postconceptional ages reflecting a higher stimulation frequency required to achieve the maximum force production. The effect was most notable at low stimulation frequencies $(5-15 \mathrm{~Hz})$ at which the relative forces in postnatal (154 d and $200 \mathrm{~d}$ ) animals were significantly lower than that in pre-term (100 d, $128 \mathrm{~d}$ and $145 \mathrm{~d})$ animals (p $<0.001)$. 


\section{Twitch contractile properties}

The twitch contractile properties for postconceptional ages 100 to $200 \mathrm{~d}$ are presented in Table 2; twitch contraction data were not recorded at $75 \mathrm{~d}$. Peak twitch force increased significantly with postconceptional age $(\mathrm{p}<0.01)$. At $100 \mathrm{~d}, \mathrm{P}_{\mathrm{t}}$ was significantly lower than $128 \mathrm{~d}, 145 \mathrm{~d}$, and $168 \mathrm{~d}$. The time to peak twitch force (TTP) at $154 \mathrm{~d}$ was significantly shorter than at $128 \mathrm{~d}(\mathrm{p}<0.05)$, whereas the relaxation times $(1 / 2 \mathrm{RT})$ at late gestation $(145 \mathrm{~d})$ and early postnatal ages (154 d, $168 \mathrm{~d})$ were significantly shorter than at $100 \mathrm{~d}$ and $128 \mathrm{~d}(\mathrm{p}<0.001)$. These data reflect a decrease in the contraction and relaxation times in the diaphragm of animals delivered near term and in the first several weeks of life. The twitch:tetanus ratio at $128 \mathrm{~d}$ was significantly greater than at all other postconceptional ages $(\mathrm{p}<0.001)$.

\section{Susceptibility to fatigue}

There was a significant main effect of postconceptional age on the fatigue index ( $\mathrm{p}<$ 0.01). The susceptibility to fatigue increased significantly from $75 \mathrm{~d}$ to $100 \mathrm{~d}$. After a decrease in fatigability at $128 \mathrm{~d}$, the susceptibility to fatigue at late gestation (145 d) and all postnatal ages (154 d to $200 \mathrm{~d}$ ) was significantly greater than at $75 \mathrm{~d}$ (Fig 2). Interestingly, the greatest susceptibility to fatigue was observed in the animals examined approximately 1 week after full term delivery (ie at $154 \mathrm{~d}$ poscconceptional age). The susceptibility to fatigue then decreased progressively with increasing postconceptional age (regression analysis between FI and PCA $154-200 ; r^{2}=0.34 ; p$ $=0.03)$. In addition, the rate of force recovery after fatigue was significantly slower in older animals (data not shown). 


\section{Susceptibility to stretch-induced muscle damage}

The susceptibility of the diaphragm muscle to stretch-induced damage at different postconceptional ages is illustrated in Fig 3. The diaphragm of $75 \mathrm{~d}$ animals was significantly more susceptible to damage compared to the older (128 d - $168 \mathrm{~d}$ ) animals ( $<<0.01$ ). There were no significant differences in susceptibility to muscle damage between any other age groups. The muscle damage protocol could not be conducted on $200 \mathrm{~d}$ lambs as the stretch protocol of $110 \% \mathrm{~L}_{\mathrm{o}}$ was beyond the capacity of the experimental apparatus for fibre length in this age group.

\section{MHC Fibre Characteristics}

The levels of mRNA expression for both MHC I and MHC IIa at each postconceptional age are shown in Fig 4A. A regression analysis of these data revealed a significant positive relationship between MHC IIa and postconceptional age $(r=0.78 ; \mathrm{p}<0.01)$. At a protein level, MHC I and MHC II content increased with postconceptional age (Fig 4B). There was a significant positive relationship between MHC I and postconceptional age $(\mathrm{r}=0.77 ; \mathrm{p}<0.01)$ and between MHC II and postconceptional age $(r=0.76 ; \mathrm{p}<0.01)$. Furthermore, MHC I and MHC II protein content were also significantly correlated to maximum specific force of the diaphragm muscle ( $\mathrm{r}=0.68 ; \mathrm{r}=0.54 ; \mathrm{p}<0.01$, respectively). MHC I protein was not detected in $75 \mathrm{~d}, 100 \mathrm{~d}$, or $128 \mathrm{~d}$ groups thus MHC type proportions at a protein level were only assessed from $145 \mathrm{~d}$ to $200 \mathrm{~d}$ postconceptional age. The MHC I:MHC II ratio decreased from $145 \mathrm{~d}$ to $154 \mathrm{~d}$ and then increased again at $200 \mathrm{~d}$ postconceptional age (Fig 4C). 


\section{DISCUSSION}

Our results show that there are significant developmental changes in contractile function and susceptibility to fatigue in the costal diaphragm of neonatal lambs. There were also changes in MHC indices evident at both an mRNA level and at a protein level which support these functional characteristics. Furthermore, the functional development of the diaphragm is likely to influence the susceptibility to damage associated with increased mechanical loading in the spontaneously breathing preterm infant.

Developmental changes in the diaphragm were observed throughout gestation up until seven weeks postnatal age (200 d postconceptional age). As the diaphragm has to be fully functional at birth, it is one of the fastest developing muscles in utero (18). We noted a significant and large decrease in the susceptibility to stretch-induced muscle damage at early postconceptional ages (75 d to $100 \mathrm{~d}$ ) and a large significant increase in specific force in late gestation (between $128 \mathrm{~d}$ and $145 \mathrm{~d}$ ) reflecting the rapid developmental changes in diaphragm function in utero. At early postconceptional ages (50 d to $100 \mathrm{~d}$ ), the limb muscles of sheep are characterised by scattered fibres (19) with poorly defined sarcomeric structure (9) and cytoskeleton. A similar immature myofibrillar structure of the diaphragm would contribute to the significantly greater susceptibility to stretch-induced muscle damage at $75 \mathrm{~d}$ postconceptional age. Eccentric diaphragm contractions in vivo produce persistent deterioration of contractile function and are associated with sarcomeric and sarcolemmal damage (20). Similar evidence of muscle damage has been observed following periods of inspiratory resistive loading $(21,22)$ which is known to heavily recruit the diaphragm (23). As the extent of diaphragm damage is load dependent (21), the pre-term 
diaphragm may be particularly susceptible to this type of damage due to the increased work of breathing and associated mechanical load on the diaphragm.

The maximum specific force in the diaphragm of preterm sheep was significantly lower than those born near term. The marked, 2-fold increase in specific force that we observed between $128 \mathrm{~d}$ and $145 \mathrm{~d}$ postconceptional age is likely attributed to the neural and hormonal factors that regulate muscle development at this gestation. This is consistent with the establishment of regular and episodic diaphragm contractions (fetal breathing movements) at around $120 \mathrm{~d}$ postconceptional age $(24,25)$ and development of the hypothalamo-pituitary-thyroid axis, which are critical in the maturational changes in muscle fibre composition $(12,18)$. The time course of these changes coincide with morphological development of the diaphragm including an increase in myofibre size and a decrease in interstitial space, and hence an increase in myofibrilar density as reported by Ashmore et al. (19) for limb muscles of sheep. In support of this notion, we observed significant increases in MHC mRNA and protein content with increasing posconceptional age and a significant, positive correlation between MHC content and maximum specific force. This increased protein content may reflect a reduction in the level of proteolytic signalling activity at gestational ages $>100 \mathrm{~d}$ in the fetal sheep (11). Thus the increase in diaphragm strength and resistance to stretch-induced damage are likely to occur in preparation for the transition to postnatal life and to accommodate the increased stress involved in the successful establishment of unsupported spontaneous breathing (26).

Along with increased strength, we also observed significant changes in other contractile parameters including decreased fatigue resistance, shorter twitch contraction times and a rightward shift in the force-frequency relationship with increasing gestational age. Our physiological data suggest a shift from slow to fast 
muscle behaviour towards late gestation which is consistent with the observations of West et al. (9) in ovine limb muscles. The resistance to fatigue was lowest at $154 \mathrm{~d}$ postconceptional age, but subsequently increased with increasing postnatal maturation. The maturational changes in fatigue resistance were consistent with the changes in twitch contraction and relaxation times which were shortest towards late gestation and the early postnatal period, and then increased again with further postnatal development. Further support for this functional slow to fast transition during late in utero development was evident from the rightward shift in the normalized force-frequency relationship reflecting an increase in the stimulation frequency required to produce a tetanic contraction.

A decrease in diaphragm fatigue resistance with increasing maturational age was demonstrated previously in a range of mammalian species including rats $(6,27)$, cats (7), baboons (8) and humans (3). As we showed in the preterm sheep, these functional properties are consistent with in vitro contractile measures including shortened twitch contraction times $(7,8,28)$, faster shortening velocities $(27)$ and a rightward shift in the force-frequency relationship $(7,28)$. Considering these contractile features, it is somewhat surprising to note that the early development of the diaphragm muscle is often characterized by an increased proportion of fatigue resistant type I muscle fibres and a corresponding decrease in type II fibres (3,6-8). This apparent discrepancy between contractile properties and histochemical fibre typing was noted previously (7) and may reflect the differential development of oxidative capacity and actomyosin ATPase activity, as reflected by MHC isoform expression $(6,29)$.

Our results indicate an increase in MHC I and MHC II protein content with maturation. However, our analysis does not reflect the neonatal isoform of MHC which is dominant in the developing diaphragm and usually co-expressed with MHC I 
and/or IIa isoforms (27). Whilst MHC I protein levels were not detected at very young gestational ages, MHC I and II were detected at higher levels towards the end of gestation which most likely coincides with the disappearance of developmental MHC isoform (2). The increase in MHC I:II ratio beyond $154 \mathrm{~d}$ postconceptional age is consistent with an increase in MHC I content during post-natal development and, along with postnatal increases in oxidative capacity $(10,11)$, may account for the increased resistance to fatigue that we observed during this postnatal period.

Although our results suggest an increased susceptibility to respiratory fatigue in term animals, extrapolation of these predictions to the clinical setting should be made with caution. It is important to note that the fatigue protocol used in this study involved maximal isometric contractions of the isolated costal diaphragm. Considering the dramatic increase in maximal force between $128 \mathrm{~d}$ and $145 \mathrm{~d}$ animals, the greater force production in the term animals may well account for the significant increase in fatigue in term animals (due to increases in the concentration of contraction-induced metabolites such as phosphate and reactive oxygen species(30)). Furthermore, as this study was restricted to the costal diaphragm, the potential contribution of the crural diaphragm to fatigue resistance is unknown. Although the oxidative capacity of the crural and costal diaphragm is not different in adult sheep (31), it is unclear whether this is true for the developing diaphragm.

Respiratory fatigue in the clinical setting reflects the balance between the work put on the diaphragm, and the diaphragm capacity. With a stable chest wall, advanced alveolar structure, and established surfactant synthesis and secretion, the relative intrinsic workload of the term infant is substantially less than that of the immature preterm infant that has a highly compliant chest wall, and minimal immature (or absent) alveoli and surfactant. The balance of this relation is such that in the absence 
of factors limiting breathing efficiency, the term diaphragm is likely to retain adequate function to overcome the intrinsic work of breathing, without needing to exert repetitive maximal contractile function. The preterm, however, is more likely to be operating closer to maximal contractile function (given lower specific force and increased intrinsic work of breathing) and therefore any level of fatigue may result in the development of insufficient spontaneous respiratory effort and respiratory failure.

The fatigue resistance of the diaphragm muscle is critical for maintaining adequate respiratory function when working against high loads. In addition to factors associated with immaturity that increase the intrinsic work of breathing, the fetus and preterm newborn may be exposed to additional environmental and iatrogenic factors that compromise the structure and function of the newborn diaphragm such as nutrition, infection, steroid exposure and mechanical ventilation. Therefore, the functional development of the diaphragm, which varies with gestational age, must be considered when evaluating the susceptibility to diaphragmatic dysfunction and the risk of developing respiratory disorders. Our studies provide an important baseline for assessment of antenatal and postnatal factors that may further compromise postnatal diaphragm integrity in the preterm ovine model.

\section{ACKNOWLEDGEMENTS}

We would like to express our sincere appreciation to Richard Dalton, Joe Dewort, and other members of the UWA and Cincinnati Children's Hospital Medical Centre Perinatal Ovine Research Collaboration for facilitating collection of these tissues and laboratory technical assistance, JRL Hall and Co. for provision and early antenatal care of the ewes, and the UWA Animal Care Unit staff. The authors have no conflict of interest to declare. 


\section{REFERENCES}

1. Dimitriou G, Greenough A, Moxham J, Rafferty GF. Influence of maturation on infant diaphragm function assessed by magnetic stimulation of phrenic nerves. Pediatr Pulm 2003;35:17-22.

2. Javen I, Williams NA, Young R, Luff AR, Walker D. Growth and differentiation of fast and slow muscles in fetal sheep, and the effects of hypophysectomy. J Physiol 1996;494:839-849.

3. Keens TG, Bryan AC, Levison H, Ianuzzo CD. Developmental pattern of muscle fiber types in human ventilatory muscles. J Appl Physiol 1978;44:909-913.

4. Maxwell LC, Kuehl TJ, McCarter RJ, Robotham JL. Regional distribution of fiber types in developing baboon diaphragm muscles. Anat Rec 1989;224:66-78.

5. Lesouef PN, England SJ, Stogryn HAF, Bryan AC. Comparison of diaphragmatic fatigue in newborn and older rabbits. J Appl Physiol 1988;65:10401044.

6. Watchko JF, Sieck GC. Respiratory muscle fatigue resistance relates to myosin phenotype and SDH activity during development. J Appl Physiol 1993;75:1341-1347.

7. Sieck GC, Fournier M, Blanco CE. Diaphragm muscle fatigue resistance during postnatal development. J Appl Physiol 1991;71:458-464.

8. Maxwell LC, McCarter RJM, Kuehl TJ, Robotham JL. Development of Histochemical and Functional-Properties of Baboon Respiratory Muscles. J Appl Physiol 1983;54:551-561. 
9. West JM, Barclay CJ, Luff AR, Walker DW. Developmental changes in the activation properties and ultrastructure of fast- and slow-twitch muscles from fetal sheep. J Muscle Res Cell M 1999;20:249-264.

10. Sieck GC, Cheung TS, Blanco CE. Diaphragm capillarity and oxidative capacity during postnatal-development. J Appl Physiol 1991;70:103-111.

11. Song Y, Pillow JJ. Ontogeny of proteolytic signaling and antioxidant capacity in fetal and neonatal diaphragm. Anat Rec (Hoboken) 2012;295:864-871.

12. Finkelstein DI, Andrianakis P, Luff AR, Walker DW. Developmental changes in hindlimb muscles and diaphragm of sheep. Am J Physiol 1992;263:R900-908.

13. Hodge K, Powers SK, Coombes J, Fletcher L, Demirel HA, Dodd SL, Martin D. Bioenergetic characteristics of the costal and crural diaphragm in mammals. Respir Physiol 1997;109:149-154.

14. Segal SS, Faulkner JA. Temperature-dependent physiological stability of rat skeletal muscle in vitro. The American journal of physiology 1985;248:C265-270.

15. Van Harmelen V, Ariapart P, Hoffstedt J, Lundkvist I, Bringman S, Arner P. Increased adipose angiotensinogen gene expression in human obesity. Obes Res 2000;8:337-341.

16. Livak KJ, Schmittgen TD. Analysis of relative gene expression data using real-time quantitative PCR and the 2(-Delta Delta C(T)) Method. Methods 2001;25:402-408. 
17. Bradford MM. A rapid and sensitive method for the quantitation of microgram quantities of protein utilizing the principle of protein-dye binding. Anal Biochem 1976;72:248-254.

18. Finkelstein DI, Andrianakis P, Luff AR, Walker D. Effects of thyroidectomy on development of skeletal muscle in fetal sheep. Am J Physiol 1991;261:R13001306.

19. Ashmore CR, Robinson DW, Rattray P, Doerr L. Biphasic development of muscle fibers in the fetal lamb. Exp Neurol 1972;37:241-255.

20. Gea J, Zhu E, Gáldiz JB, Comtois N, Salazkin I, Fiz JA, Grassino A. Functional consequences of eccentric contractions of the diaphragm Arch Bronconeumol 2009;45:68-74.

21. Jiang T-X, Reid WD, Belcastro A, Road J. Load dependence of secondary diaphragm inflammation and injury after acute inspiratory loading. Am J Respir Crit Care Med 1998;157:230-236.

22. Reid WD, Huang J, Bryson S, Walker DC, Belcastro AN. Diaphragm injury and myofibrillar structure induced by resistive loading. J Appl Physiol 1994;76:176184.

23. Road J, Osborne S, Cairns A. Phrenic motoneuron firing rates during brief inspiratory resistive loads. J Appl Physiol 1995;79:1540-1545.

24. Dawes GS, Fox HE, Leduc BM, Liggins GC, Richards RT. Respiratory movements and paradoxical sleep in the foetal lamb. J Physiol 1970;210:47P-48P. 
25. Harding R, Bocking A. Fetal growth and development: Cambridge University Press; 2001.

26. Bowes G, Adamson TM, Ritchie BC, Dowling M, Wilkinson MH, Maloney JE. Development of patterns of respiratory activity in unanesthetized fetal sheep in utero. J Appl Physiol 1981;50:693-700.

27. Zhan W-Z, Watchko JF, Prakash YS, Sieck GC. Isotonic contractile and fatigue properties of developing rat diaphragm muscle. J Appl Physiol 1998;84:12601268.

28. Moore BJ, Feldman HA, Reid MB. Developmental changes in diaphragm contractile properties. J Appl Physiol 1993;75:522-526.

29. Watchko JF, Daood MJ, Sieck GC. Myosin heavy chain transitions during development. Functional implications for the respiratory musculature. Comp Biochem Physiol B Biochem Mol Biol 1998;119:459-470.

30. Allen DG, Lamb GD, Westerblad H. Skeletal muscle fatigue: cellular mechanisms. Physiol Rev 2008;88:287-332.

31. Hodge K, Powers SK, Coombes J, Fletcher L, Demirel HA, Dodd SL, Martin D. Bioenergetic characteristics of the costal and crural diaphragm in mammals. Respir Physiol 1997;109:149-154. 

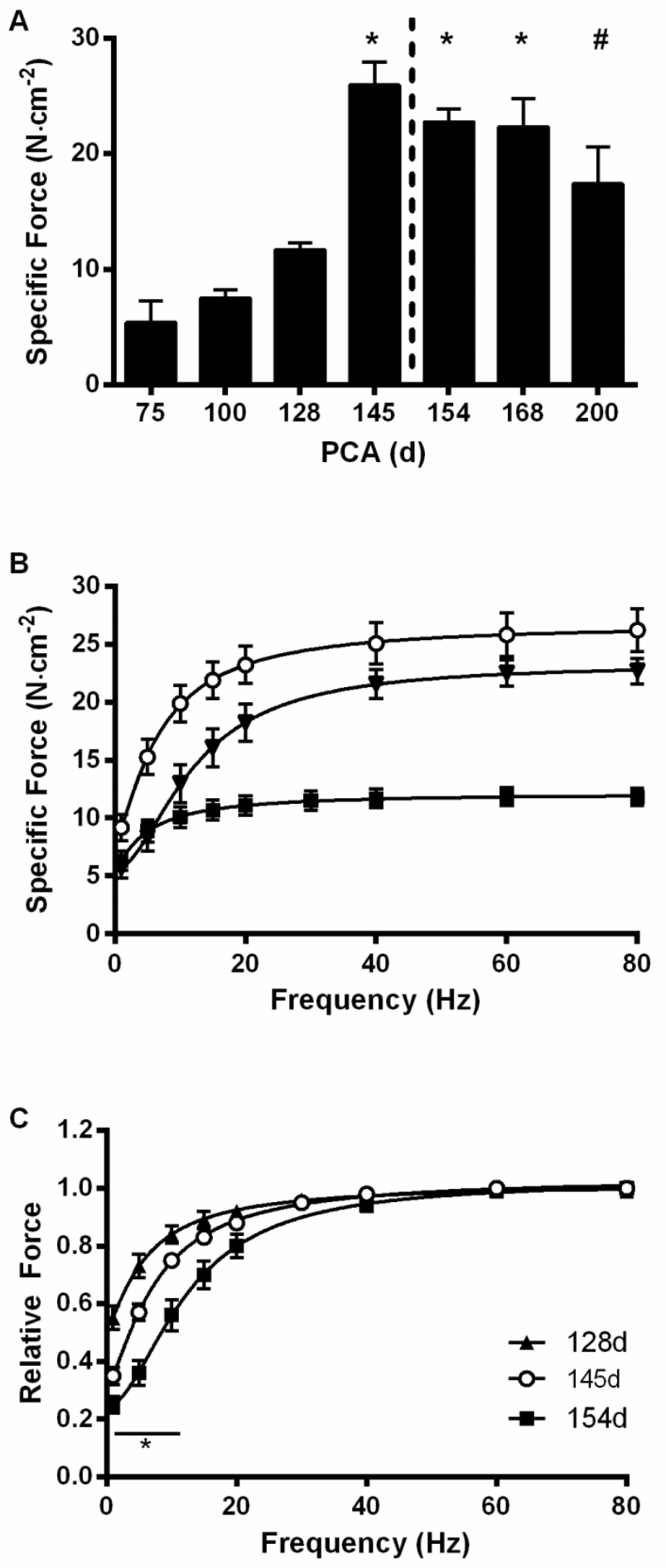

Figure 1 - Specific Force and Force-Frequency Relationships: A. Mean ( \pm SEM) maximum specific force at different postconceptional ages (PCA). * significantly different from $75 \mathrm{~d}, 100 \mathrm{~d}$, and $128 \mathrm{~d}$; \# significantly different from $75 \mathrm{~d}$ and $100 \mathrm{~d}$ (p $<0.001)$. Vertical line indicates change from fetal to postnatal life. B. Mean ( \pm SEM) specific force-frequency relationships at three different postconceptional ages, $128 \mathrm{~d}$, $145 \mathrm{~d}$ and $154 \mathrm{~d}$. C. Mean ( \pm SEM) normalised force frequency relationships at $128 \mathrm{~d}$, $145 \mathrm{~d}$ and $154 \mathrm{~d}$. * $154 \mathrm{~d}$ is significantly different to $128 \mathrm{~d}$ and $145 \mathrm{~d}$ (p < 0.05). 


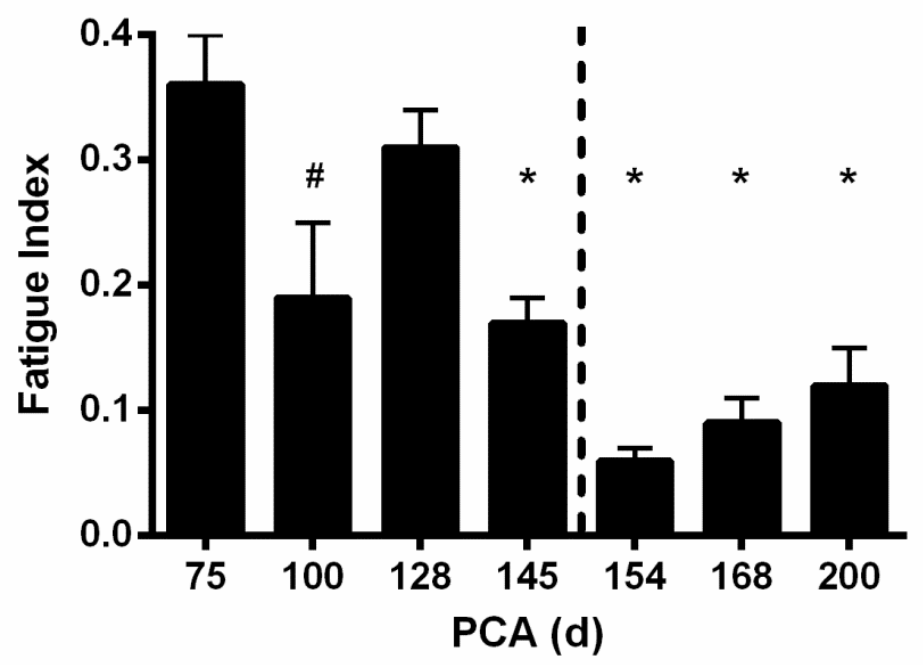

Figure 2 - Fatigue Resistance: Mean ( \pm SEM) fatigue index (FI) across different postconceptional ages. The fatigue index was expressed as the force produced during the last fatiguing contraction relative to the first contraction, for which higher number indicates greater fatigue resistance. * significantly different from $75 \mathrm{~d}$ and $128 \mathrm{~d}$; \# significantly different from $75 \mathrm{~d}(\mathrm{p}<0.001)$. Vertical dotted line indicates change from fetal to postnatal life. 


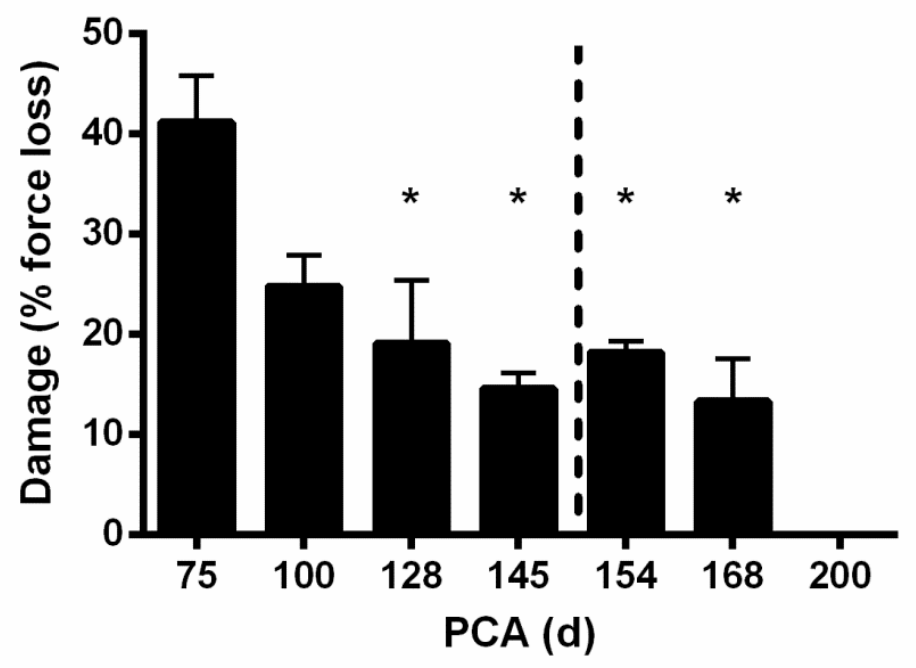

Figure 3 - Muscle Damage: Mean $( \pm$ SEM) decrease in maximal tetanic force after muscle stretch protocol. Muscles were exposed to five eccentric contractions of $10 \%$ $\mathrm{L}_{0}$ applied on the plateau of a tetanic contraction. * significantly different from $75 \mathrm{~d}$ $(p<0.01)$. Vertical line indicates change from fetal to postnatal life. 
A

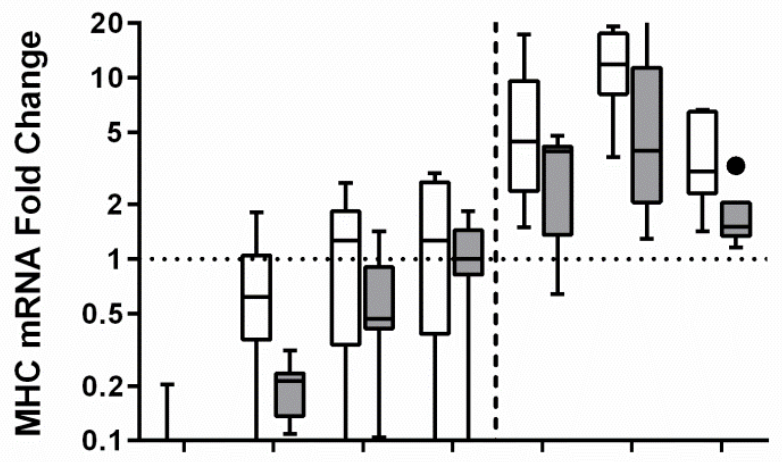

B
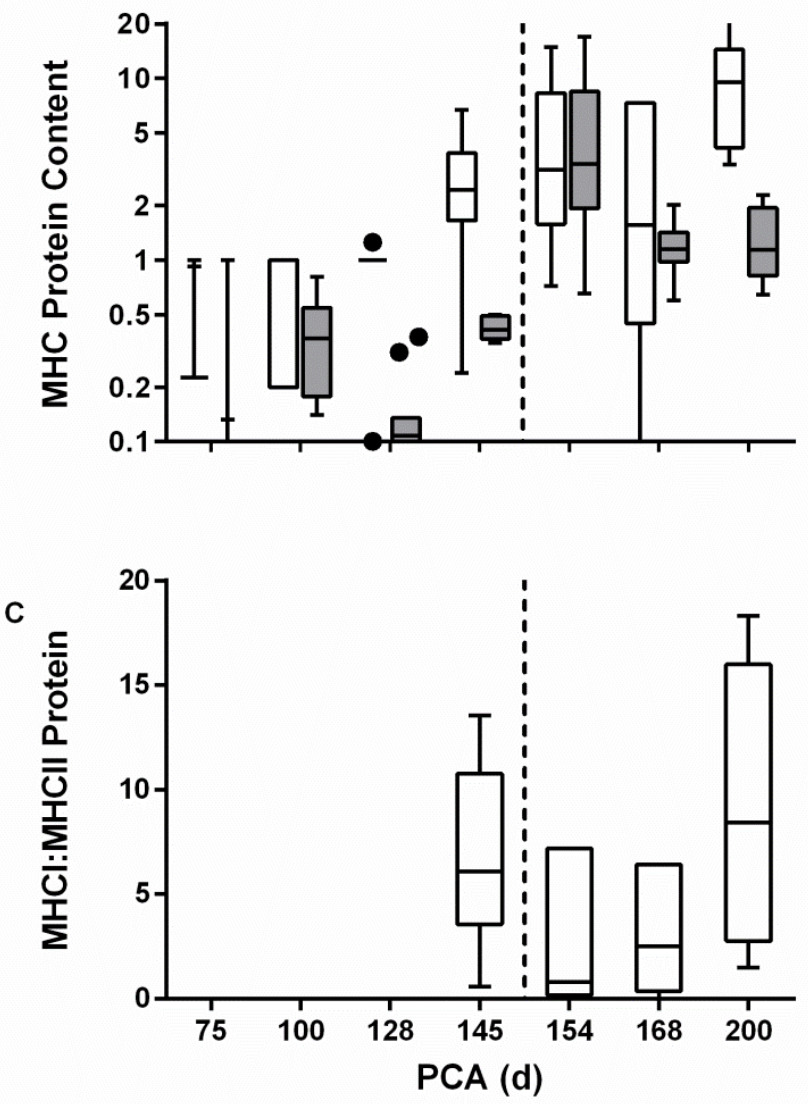

Figure 4 - MHC mRNA and Protein: Fold change in MHCI (white) and MHCIIa (grey) mRNA expression (A) and MHCI (white) and MHCII (grey) protein content (B). Ratio of MHCI:MHCII protein content (C) in diaphragm tissue homogenate. Values are median $\left(25^{\text {th }}, 75^{\text {th }}\right.$ centile). Error bars show $10^{\text {th }}$ and $90^{\text {th }}$ centile. Black dots represent outlying values. Vertical line indicates change from fetal to postnatal life. Horizontal dotted line in (A) represents median of reference (145d) group. 